\title{
Pompe's Disease or Type IIa Glycogenosis
}

\author{
José Luiz Balthazar Jacob, Rosiene Lisboa Leandro, A delino Parro Jr
}

São José do Rio Preto, SP - Brazil

This is the report of a five-month-old child presenting clinical evidence of Pompe's disease: severe hypotonicity, hyporeflexia and congestive heart failure. The ECG showed a short PR interval, the chest radiography disclosed marked cardiomegaly, and the echocardiogram revealed marked left ventricular hypertrophy - the most typical finding of this disease.

A skeletal muscle biopsy led to final diagnosis, because in the histopathologic study marked increased glycogen accumulation was evident. Death occurred two months after symptom onset.

Glycogen storage disease (GSD) is a rare, inherited defect which leads to glycogen accumulation in one or more body tissues. Type IIa glycogenosis - or Pompe's disease - is a classical infantile form, fatal in the first 24 months, and characterized by progressive accumulation of glycogen in body tissues, especially the myocardium, skeletal muscles and liver ${ }^{1-3}$.

Glycogen accumulation is caused by the deficiency of an enzyme - alpha-1,4 glucosidase (lysosomal glucosidase; acid maltase) via autosomal recessive inheritance ${ }^{1-3} \cdot$ In this report the authors describe a typical case of Pompe's disease diagnosed not only based on a physical examination but also based on electrocardiographic, radiological and echocardiographic findings, and confirmed in biopsies of the skeletal muscles.

\section{Case Report}

A five-month-old Caucasian girl had a history of a normal birth and no neonatal medical complications. When she was three months old, the infant had difficulty sucking, tiredness during feeds and excessive sweating. The infant was hospitalized in Uberlândia, Minas Gerais State, and heart disease and associated pulmonary infection were diagnosed. During hospital admission the infant presented with lassitude and difficulty in moving in the cradle. As the infant's condition did not improve, she was transferred to our Service. In the patient's history the mother reported that her first two children had died in the age of 5 and 6 months

Instituto de Moléstias Cardiovasculares - São José do Rio Preto Mailing address: José Luiz Balthazar Jacob - IMC - Rua Castelo D’Água, 3030 15015-210 - São José do Rio Preto, SP - Brazil.

Received on 12/8/98

Accepted on 5/19/99 old, respectively, with similar symptoms as those present in the infant patient. The parents were first degree cousins.

The physical examination showed a child underdeveloped for her age, with tachypnea, hypotonicity and macroglossia. All pulses were present although with decreased amplitude and a rate of $140 \mathrm{bpm}$. Her blood pressure was $80 /$ $50 \mathrm{mmHg}$, precordial auscultation revealed triple gallop and a mild ++/6 systolic mitral murmur. Rales were audible at both pulmonary bases. The liver was palpable at $3 \mathrm{~cm}$ below the costal margin. Neuropediatric assessment revealed severe hypotonicity and diffuse hyporeflexia, accompanied by the lack of response to some stimuli. The ECG showed short PR interval, sinus rhythm and left ventricular hypertrophy, with $\mathrm{T}$ wave inversion in the inferior and lateral walls (fig. 1A). The chest $X$-ray revealed cardiomegaly and pulmonary venous hypertension (fig. 1B). Doppler echocardiography showed severe left ventricular hypertrophy, with cavity diameter enlargement and systolic dysfunction (fig. 2 A-B). Mild-to-moderate mitral valve regurgitation was observed on Doppler analysis. No obstructive processes were found. After diuretics and digitalis were administered to the infant, her dyspnea improved slightly.

Clinical, electrocardiographic and echocardiographic data led to our decision to perform a skeletal muscle biopsy of the thigh. The pathologic examination revealed glycogen storage accumulation forming diffusely scattered vacuoles throughout the muscle fragments (fig. 3). Diagnosis: Type IIa glycogen storage disease, or Pompe's disease. Two days after the biopsy the infant experienced repeated crises of apnea. An endotracheal tube was placed and maintained for $24 \mathrm{~h}$, when the infant was tachycardiac and hypotensive despite vasoactive drugs. Asystole and death followed.

\section{Discussion}

Glycogen storage diseases are associated with over 15 different enzyme deficiencies, and can be clinically divided into two groups: those affecting primarily the liver and those affecting primarily the muscles ${ }^{4}$. Type IIa glycogenosis can be diagnosed microscopically between the $15^{\text {th }}$ and the $18^{\text {th }}$ week of pregnancy in amniotic liquid cells ${ }^{5}$. An early postnatal clinical diagnosis is not easy, since muscle tonus and liver size are normal at birth and in the first weeks after birth. Later on, approximately after one month or a little later, the infant becomes flaccid, starts to have difficulty sucking and there is concurrent cardiac enlargement revealed by 

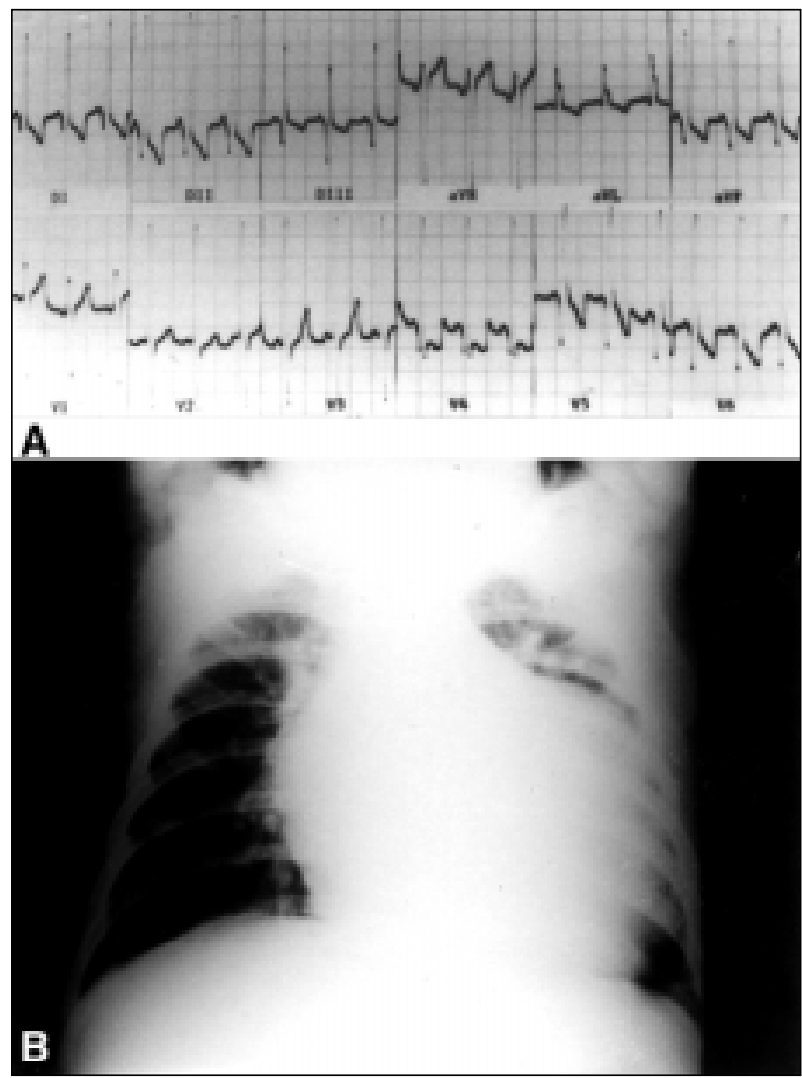

Fig. 1 -A) The electrocardiogram shows sinus rhythm with a short PR interval with left ventricular hypertrophy. Note the deep Q waves in the inferior and lateral walls; B) the chest film demonstrates severe cardiomegaly and pulmonary congestion with increased perfusion of the left lung apex.

chest film ${ }^{1-3}$. Hypotonicity results from progressive glycogen accumulation in the muscles and in the nervous system. Macroglossia aggravates the hypotonic child's inability to suck or swallow, and results in aspiration pneumonia ${ }^{1,2}$. Our patient presented with the classical clinical signals of the condition. Muscular weakness, hypotonicity, and hyporeflexia started in the third month after birth and evolved quickly. Initial manifestations were congestive heart failure and pulmonary infection. Electrocardiographic findings were similar to those reported by other authors, including short PR interval and high voltage QRS complexes due to left ventricular hypertrophy ${ }^{1,3}$. In the present case, deep left precordial and inferior $\mathrm{Q}$ waves occurred, with $\mathrm{T}$ wave inversion in different leads. PR interval shortening is a result of the reduction of the conduction time between right atrium and the His' bundle ${ }^{1}$. An isolated case is described where the electrogram showed severe postnatal bradycardia associated with breathing problems. For that reason, it is suggested that metabolic cardiomyopathies be included in the differential diagnosis of bradycardia in the newborn ${ }^{6}$. Cardiomegaly documented by chest films is a constant finding reported in the literature, because cardiac mass can be from three to ten times larger as a result of glycogen accumulation than that which would be expected for the child's age ${ }^{1,3}$. The hallmark echocardiographic findings is severe left ventricular hypertrophy, both in the septum and in other walls, which can result in decreased cavity volume. Cavity reduction may lead to diminished ventricular compliance and left ventricular out-flow tract obstruction ${ }^{1}$. In spite of severe hypertrophy, our patient presented an enlarged left ventricle and systolic dysfunction. Such data are absolutely essential for the prescription of digitals, since it may aggravate the condition of patients who have left ventricular obstruction. Some patients may benefit from the use of a beta-blocker ${ }^{1}$. For patients with Pompe's disease, treatment is solely supportive to improve congestive heart failure symptoms, basically with diuretics and a careful use

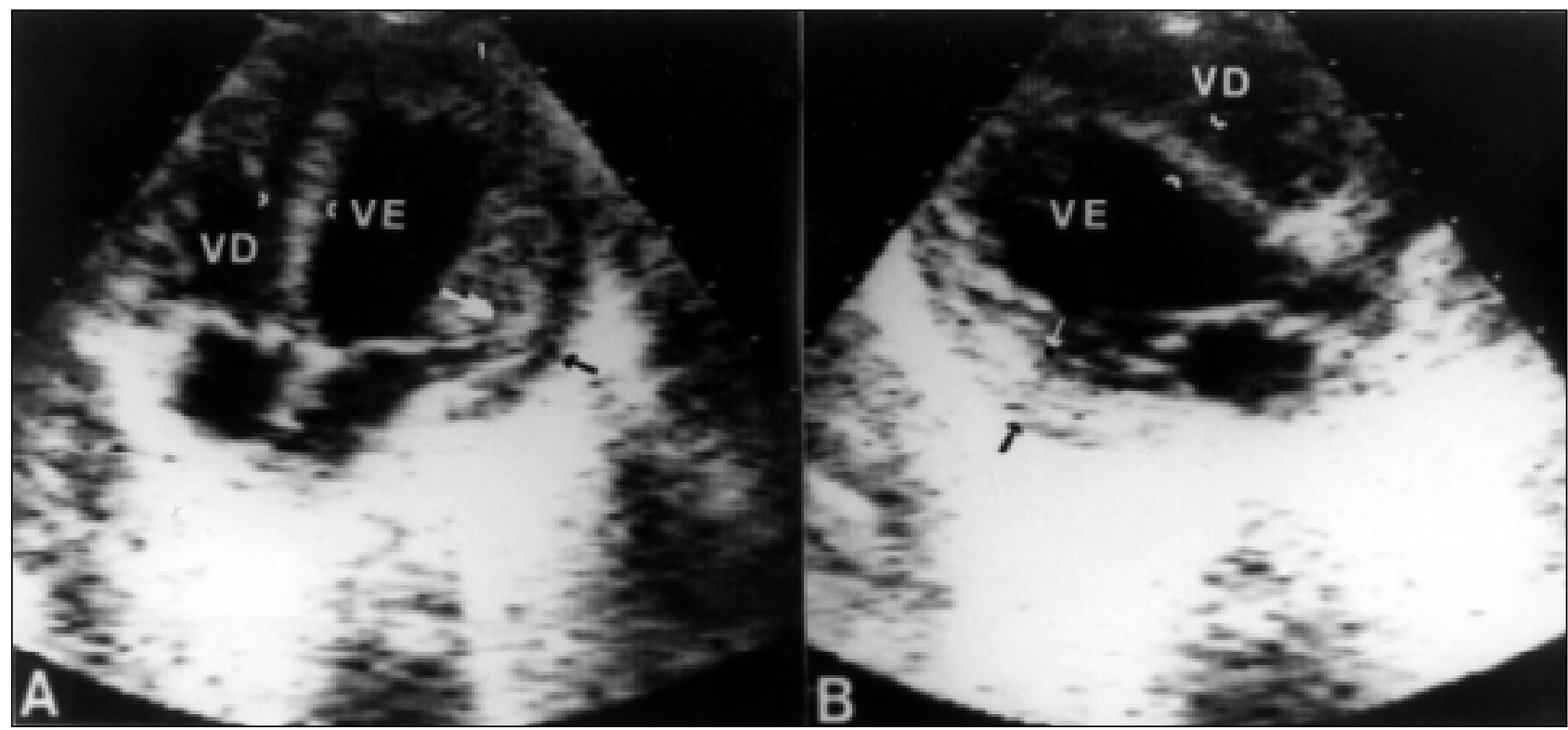

Fig. 2-Echocardiogram in the apical four chamber (A) and long axix (B) views, showing left ventricular hypertrophy. Note the increased left ventricular diameter. Septal thickness $=7.5 \mathrm{~mm}$ (normal value $<5 \mathrm{~mm}$ ), posterior wall thickness $=9 \mathrm{~mm}$ (arrows; normal value $<5 \mathrm{~mm}$ ); diastolic diameter $=35 \mathrm{~mm}($ normal for age $<24 \mathrm{~mm}$ ); ejection fraction $=30.5 \%$; left ventricular mass $98.5 \mathrm{~g}$ (normal for age $<28 \mathrm{~g}$ ). $\mathrm{LV}$ mass $/$ body surface $=339.6 \mathrm{~g} / \mathrm{m}^{2}$ (normal value $\left.<96 / \mathrm{m}^{2}\right)$. 


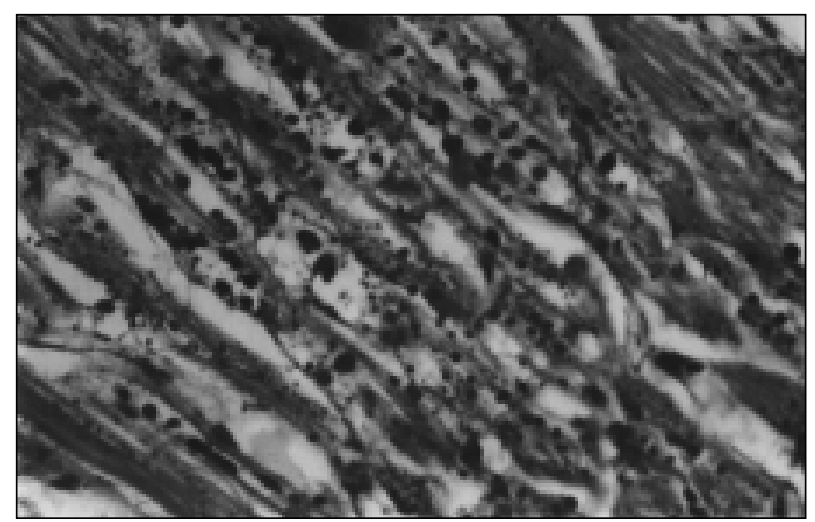

Fig. 3 - Aspectohistopatológico de um corte do fragmento de músculo esquelético da paciente corado pelo PAS (reativo de Schiff), que confere ao glicogênio uma cor vermelho magenta ou carmim. Nota-se os vacúolos de glicogênio (em vermelho) difusamente infiltrados entre as fibras musculares. of digitalis which, even in patients without left ventricular obstruction, may trigger arrhythmia because of extreme myocardial sensitivity and excitability. Skeletal muscle biopsy is necessary for the diagnosis, with evidence of increased glycogen content - which may be as high as seven times greater than normal muscle ${ }^{1,2}$. Death results from respiratory muscle failure ${ }^{1}$. Our patient experienced repeated episodes of apnea. The present report is relevant not only because it reports on a rare disease, but also as a reminder that Pompe's disease should be included in the differential diagnosis of diseases leading to congestive heart failure in young children. Testing for Pompe's disease is imperative for family guidance because of the risk of its transmission to future children. The other two children of the couple died within the first months after birth with similar clinical conditions, thus suggesting that the cause of death might have been the same.

\section{References}

1. Caddell JL. Metabolic and nutritional disease. In: Adams FH, Emmanouilides GC, Riemenschneider TA, eds. Heart Disease in Infants, Children, and Adolescents, $4^{\text {th }}$ ed. Baltmiore: Willians e Wilkins 1989: 753-55.

2. Hug G. Inborn errors of metabolism. In: Nelson WE, Behrman RE, Vaughan VC, eds. Textbook of Pediatrics, $12^{\text {th }}$ ed. Philadelphia: WB Saunders Co 1983: 460-1.

3. Ettedgui JA. Cardiological aspects of systemic disease. In: Anderson RH, Macartney FJ, Shinebourne EA, Tynan M. eds. Pediatric Cardiology. Edinburgh: Churchill Livingstone 1987: 1.246.
4. Shin YS. Diagnosis of glycogen storage disease. J Inherit Metab Dis 1990; 13: 419-34.

5. Hug G, Soukup S, Ryan M, Chuck G. Rapid prenatal diagnosis of glycogenstorage disease type II by electron microscopy of uncultured ammiotic-fluid cells. N Engl J Med 1984; 310: 1018-22.

6. Van Maldergem L, Haumont D, Saurty D, Jauniaux E, Loeb H. Bradycardia in a case of type II glycogenosis (Pompe's disease) revealing in early neonotal period. Acta Clin Belg 1990; 45: 412-4. 